Online Supplement

\title{
Platelet activation at the onset of human endotoxemia is undetectable in vivo
}

\author{
Waltraud Cornelia Schrottmaier ${ }^{1}$, Julia Barbara Kral ${ }^{1}$, Markus Zeitlinger ${ }^{2}$, \\ Manuel Salzmann ${ }^{1}$, Bernd Jilma ${ }^{2}$, Alice Assinger ${ }^{1}$
}

${ }^{1}$ Centre of Physiology and Pharmacology, Medical University of Vienna, Vienna, Austria,

${ }^{2}$ Department of Clinical Pharmacology, Medical University of Vienna, Vienna, Austria

\section{Effects of different doses of LPS on platelet activation in vitro}

To further study the effects of LPS on platelet function in vitro, we aimed at stimulating platelets with similar LPS concentrations as in our endotoxemia model.

We assumed that injection of $2 \mathrm{ng} / \mathrm{kg}$ body weight (approximately $150 \mathrm{ng}$ LPS per healthy, male volunteer), let to a LPS plasma concentration of approximately 50 $\mathrm{pg} / \mathrm{ml}$ (150ng /3 I plasma as hydrophilic substances primarily distribute to the plasma compartment). As it takes approximately three lung passages to equally distribute a substance in blood, LPS concentrations might be altered at the beginning of infusion, while at later time points LPS levels will drop due to LPS-cell interactions. Therefore we tested the effect of 25, 50 and $100 \mathrm{pg} / \mathrm{ml}$ LPS on surface expression of P-selectin and GPIlb/IIla activation in platelet-rich plasma (PRP). As depicted in supplemental Fig. 1 no significant differences in platelet activation were observed between 25, 50 and $100 \mathrm{pg} / \mathrm{ml}$ LPS. Of note, no significant changes in platelet activation were 
observed between 0 and 60 min without addition of any agonists, indicating that untreated platelets remained in a resting state within the investigated time frame.
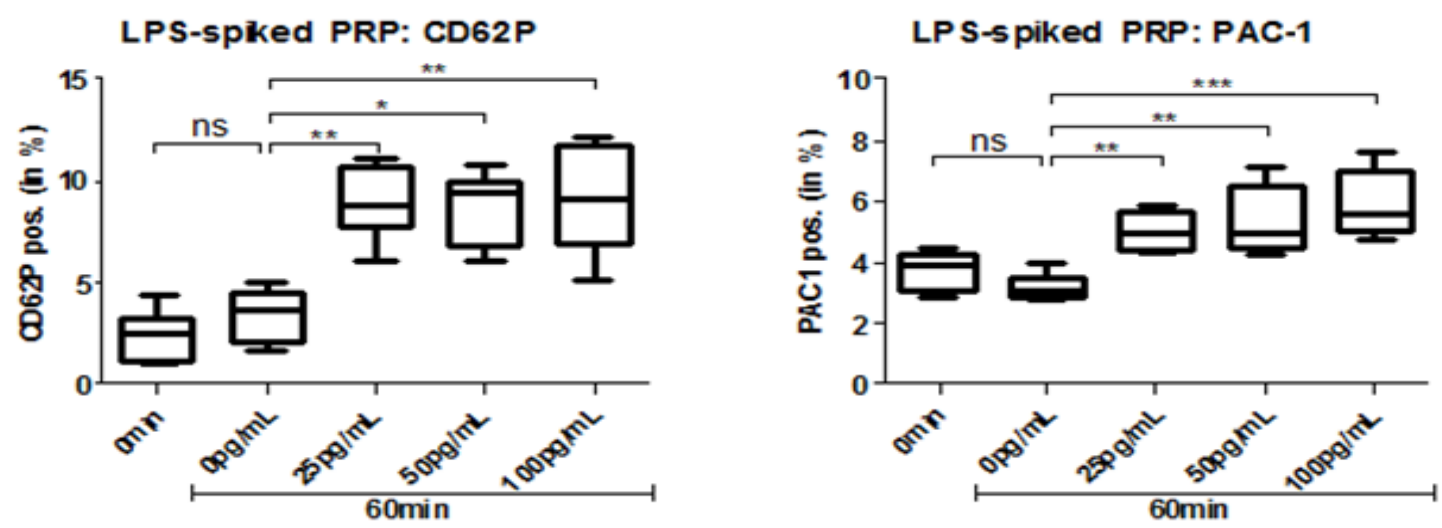

Supplemental figure 1: Platelet activation in response to $25-100 \mathrm{pg} / \mathrm{ml}$ LPS. PRP was spiked with LPS (25 pg/mL, $50 \mathrm{pg} / \mathrm{mL}$ or $100 \mathrm{pg} / \mathrm{mL}$ ) for $60 \mathrm{~min}$. Platelet activation was determined at basal level (0min, 60min) and after LPS spike (60 min) by measuring surface P-selectin (CD62P) expression (left panel) and GPIlb/Illa activation (PAC-1, right panel) as described in the Materials and Methods section of the manuscript. Statistics by repeated measures ANOVA with Bonferroni's multiple comparison test. $\mathrm{n}=9$ for $\mathrm{CD} 62 \mathrm{P} ; \mathrm{n}=5$ for $\mathrm{PAC}-1$;

\section{Effect of LPS on endothelial cell activation within 4 minutes of stimulation}

To rule out that platelet adhesion to endothelial cells in response to LPS stimulation was a result of endothelial cell activation, we measured endothelial cell activation after 4 minutes of stimulation with LPS.

Due to that short time of stimulation, neither de novo protein synthesis nor integrin expression can be observed. Only rapid events like exocytosis of Weibel Palade bodies are possible. Due to flow conditions released cytokines cannot be measured. Therefore we determined endothelial cell activation after 4 minutes of LPS stimulation by P-selectin via immune histochemistry. 
As shown in supplemental Figure 2 we did not observe any significant differences in

VE-cadherin or P-selectin expression.
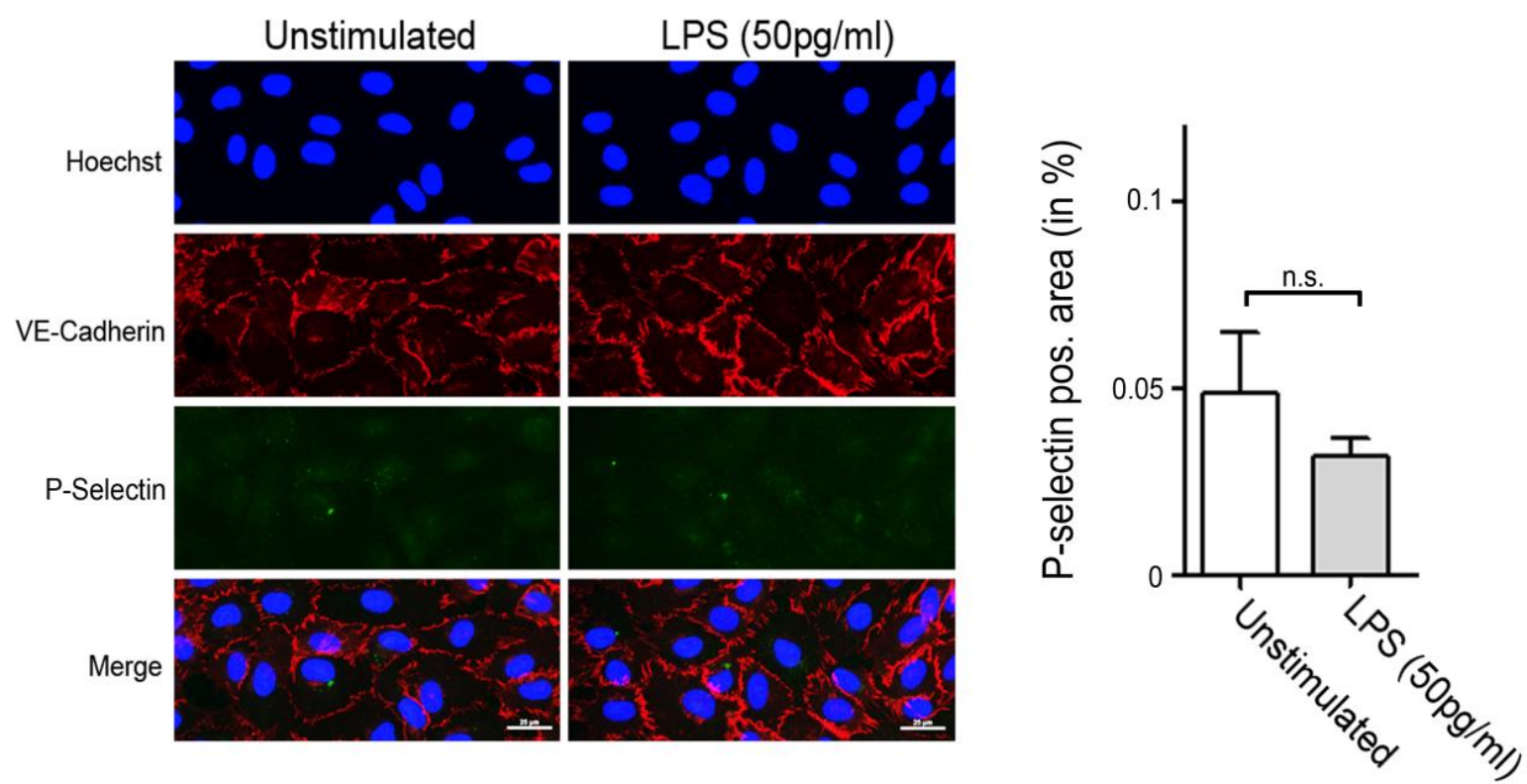

Supplemental figure 2: P-selectin expression of HUVECs after LPS $(50 \mathrm{pg} / \mathrm{ml})$ perfusion. HUVECs were perfused with $50 \mathrm{pg} / \mathrm{ml}$ LPS for $4 \mathrm{~min}$, followed by a 10 min washout phase and immediate fixation with $1 \%$ PFA. Cells were stained for Pselectin (1:100, 60 min, BioLegend), VE-Cadherin and Hoechst (as described in the Materials and Methods section of the manuscript). P-selectin expression was quantified as percentage of P-selectin positive area using ImageJ. Representative pictures and mean $\pm S D$ are given. $n=3$ 